\title{
Effect of print orientation using DMLS method on strength of materials
}

\author{
Rafael Miozga ${ }^{1 *}$, Marta Kurek $^{1}$ \\ ${ }^{1}$ Faculty of Mechanical Engineering, Opole University of Technology, 45-407 Opole, Mikołajczyka \\ 5 , Poland
}

\begin{abstract}
The paper reported the results of a study concerned with the principle of operation of the $3 \mathrm{D}$ printing technology using the method of selective sintering of metallic powders, and taking into account their advantages and drawbacks. The principle of the operation of 3D printing technology applying the DMLS (Direct Metal Laser Sintering) method is presented. On the basis of the performed tests, the anisotropy of the printed materials is demonstrated. The reasons responsible for this phenomenon are identified. The paper presents the results of the strength tests which indicate that the crack during the test occur in the building direction of the layers during printing. The results were compiled for two different types of specimens and two different testing machines.
\end{abstract}

\section{Introduction}

Over the past few years, there has been a great progress in the development of $3 \mathrm{D}$ printing technology, in particular in the areas related to the production of plastic elements. Progress is determined by the versatile use of this technology in industry and the patent release of a given manufacturing method. In addition, 3D printing offers the possibility of producing low-serial construction elements with a complex design that are difficult to manufacture and costly using traditional manufacturing techniques. 3D printing technology involves the building and bonding of successive layers of material with parameters characterized by an adequate structure and thickness. As a result of applying subsequent layers, a compact model is formed that constitutes a final product or a semi-finished product. In most cases, 3D printing requires further processing, most often associated with removing supports or finishing the printed surface. Despite many advantages, this technology also involves drawbacks such as the need to remove the model supports or use finishing machining to generate a better surface [1-4]. However, one of the biggest drawbacks is the anisotropy in the structure of the material. The aim of the study reported here is to analyze the influence of the printout orientation using the DMLS method on the strength of the tested material. The scope of work includes: development of threedimensional models of specimens for experimental research and printing strategies; performing a static tensile test for flat and round specimens printed at different angles and

* Corresponding author: r.miozga@doktorant.po.edu.pl 
analysis of the results. The specimens applied in the experiment were made using Maraging Steel MS1 tool steel.

\section{DLMS printing method}

The DLMS method forms one of teh methods that applying metalic powders. The diagram that illustrates the process of DLMS printing is presented in Fig 1 and this method involves the following steps:

- $\quad$ applying inert gas and preheating of the printing chamber,

- $\quad$ spreading a thin layer of adeaquately composed metallic powder through a recoater (application device),

- initial scanning of the cross-section of the element high-power laser,

- selective melting of a metallic powder particles,

- reduction of the platform by a value corresponding to the thickness of a single layer of material,

- distribution of a thin layer of metallic powder through a recoater (application device)

- repeating the process until the full geometry of the object is built,

- removing the full model from the printing base platform after the finished process

- removing supports and performing surface finishing procedures

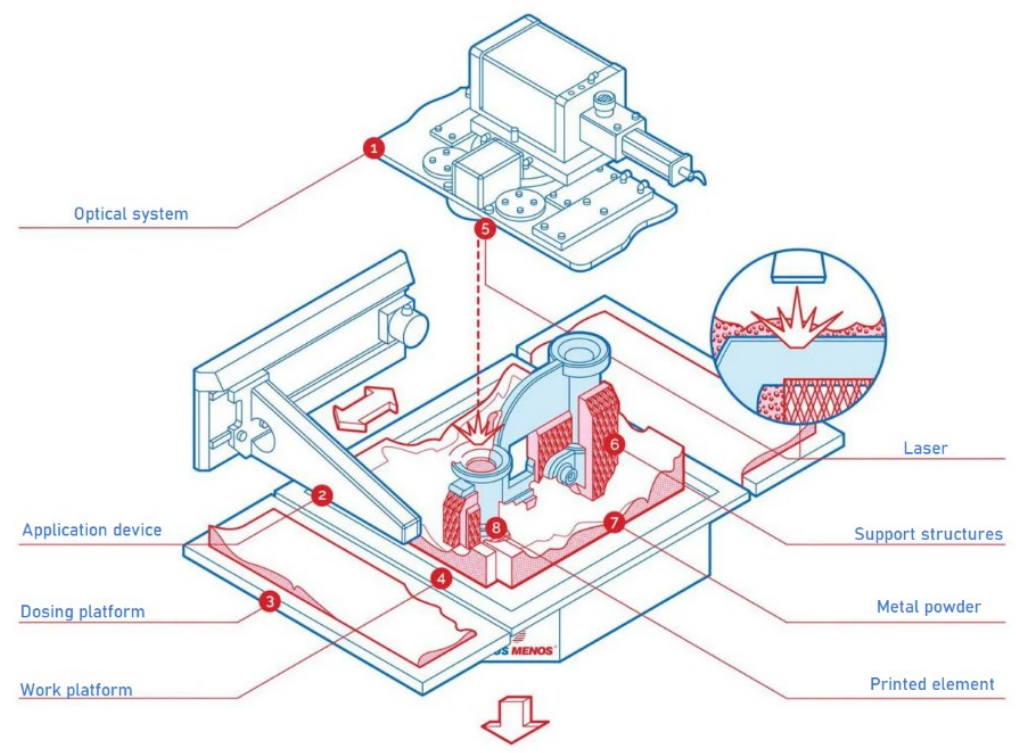

Fig. 1. Schematic illustration of the DMLS printing method [5]

The printing carried out using of the DMLS method consists in applciation of layers of the material in the element and hardening it in this place by surfacing of the print line. Local stresses occur in the material as a result of acting temperatures and the variable time of application of subsequent layers, and this contributes to heterogeneity of the 
material structure. These inhomogeneities are layered (they are located along the direction of the layers of the print line). This has a great influence on the strength of the element. The negative impact of anisotropy may be improved by the use of heat treatment of the finished element.

Due to the possible occurrence of anisotropy in the material, tests will be carried out for specimens printed at different angles. The specimens prepared in this manner will be applied to research concerned with determining whether the arrangement of the infill layers has an impact on the strength of the tested material.

\section{Anisotropy of elements produced by 3D printing method}

Anisotropy is defined as the differentiation of the value of a given parameter depending on the direction of the measurement. The anisotropy of printed elements results from the layered bonding of the material as a consequence of using elevated temperature [6,7]. Fig. 2 shows the process of layer formation during laser sintering. In addition to the formation of layers, you can also see the undulations of the material and the heterogeneity also occurring between the individual printing paths.

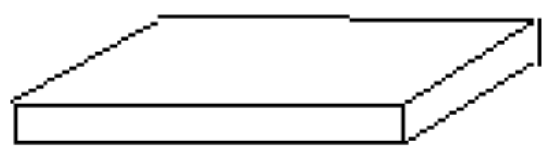

(a)

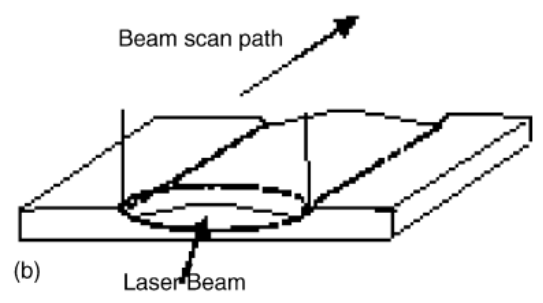

(b)

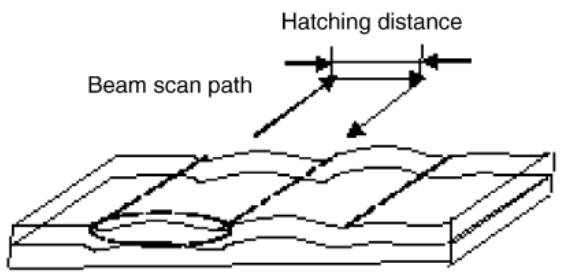

(c)

Fig. 2. Schematic illustration of laser sintering. a) prior to sintering, b) finished single scanning path, c) generation of sintering layer [8]

Fig. 3 contains details of the building direction of layers in relation to the direction of print. The layered structure occurs in the entire material and is arranged perpendicular in relation to the direction of layer application and its height overlaps with the thickness of the printed layer. 


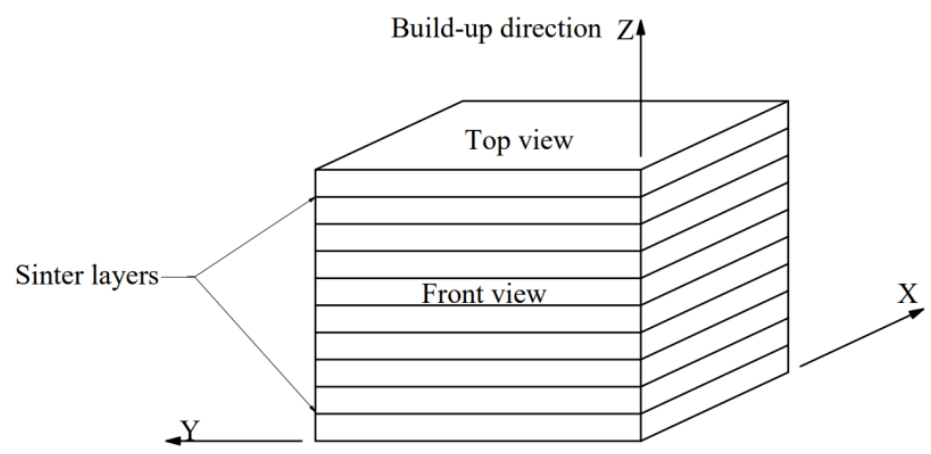

Fig. 3. Structure of layers in the material in relation to the print direction

There are a number of publications on the strength properties of elements made with the additive method [9-11]. The publications available currently mainly involve plastic components, but few studies are concerned with the strength of components made by selective sintering of metal powder. Due to the fact that scientific research contains few studies on the printing technology based on the method of selective bonding of metal powders, this paper focuses on comprehensive aspects regarding the strength of elements generated by the DLMS method.

\section{Experimental research}

\subsection{Material and specimens}

The methodology appeid in the preparation of the specimens is presented in Fig. 4. The specimens were printed on an EOSINT M280 printer. The printing strategy included printing at different angles: $45^{\circ}, 60^{\circ}, 75^{\circ}, 90^{\circ}$ in relation to the printing surface.

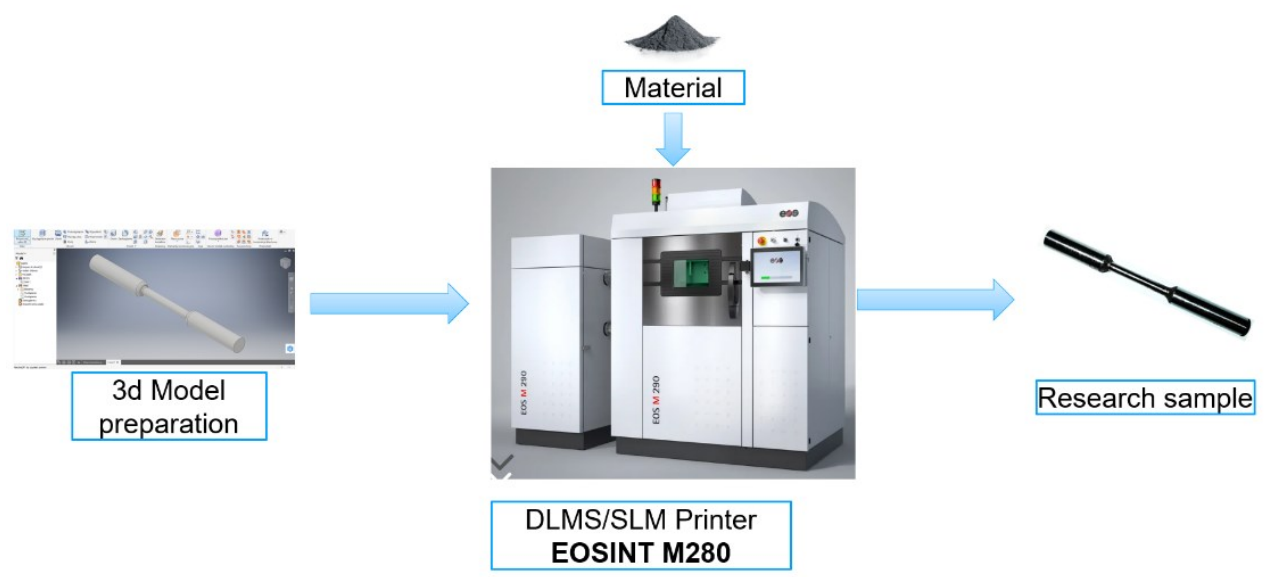

Fig. 4. Scheme followed in the preparation of specimens

Flat specimens (Fig. 5) and round specimens (Fig. 6) were applied for strength tests. The specimens are made of Maraging Steel MS1 steel powder. The height of the printed layer was $40 \mu \mathrm{m}$ In tab. 1 lists the static properties of the tested material immediately after printing (based on manufacturer's data) 
Table 1. Static properties of MS1steels

\begin{tabular}{|c|c|c|}
\hline $\mathrm{R}_{\mathrm{m}}$ & $\mathrm{R}_{0,2}$ & $\mathrm{~A}_{5}$ \\
{$[\mathrm{MPa}]$} & {$[\mathrm{MPa}]$} & {$[\%]$} \\
\hline 1200 & 1020 & 13 \\
\hline
\end{tabular}

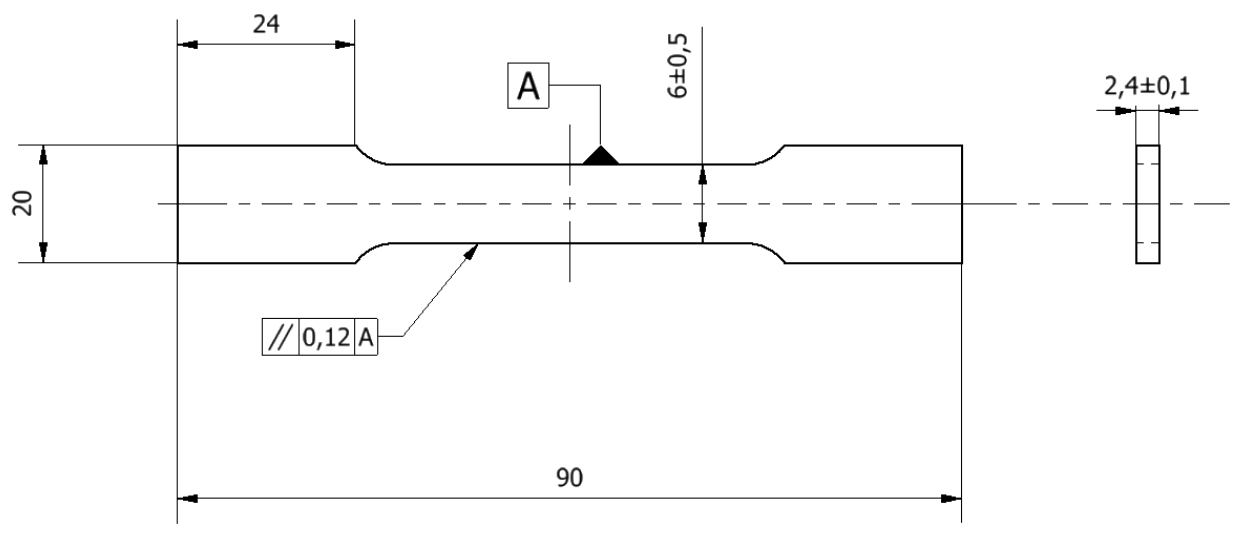

Fig. 5. Geometry of flat specimens

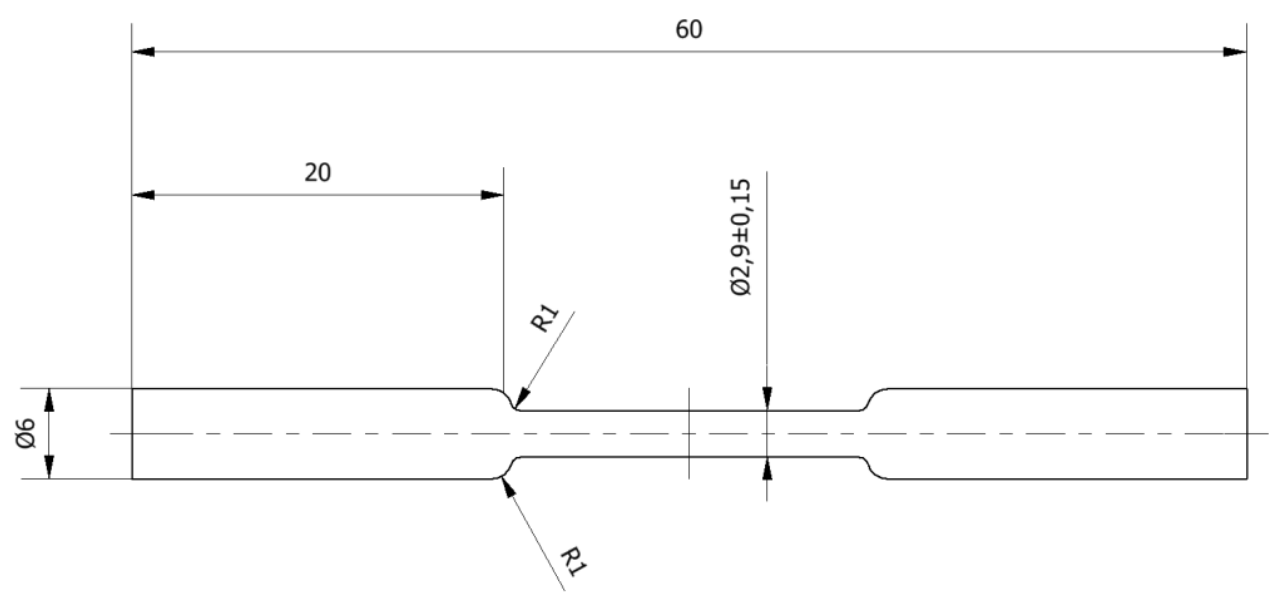

Fig. 6. Geometry of round specimens

The tests were conducted by applciation of (Figs. 7-8) Instron 8802 (for flat specimens) and Instron ElectroPlus E10000 test system (for round specimens). 


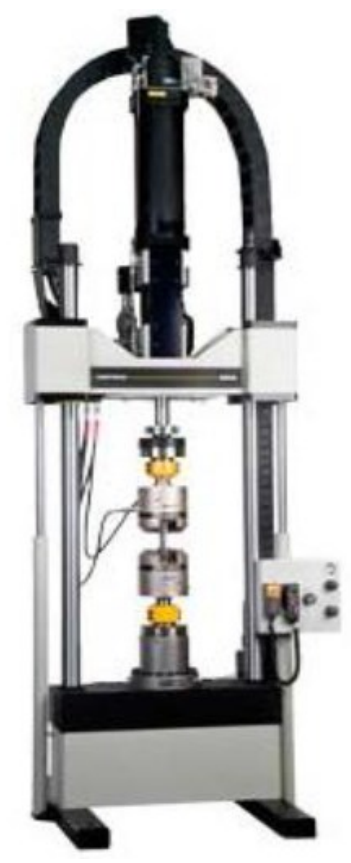

Fig. 7. Instron 8802

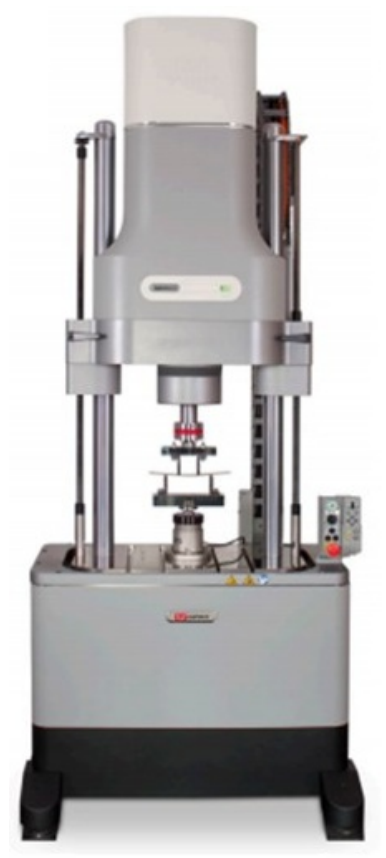

Fig. 8. Instron ElectroPlus E10000

\section{Analysis of the results}

As part of the study, a tensile test was carried out, which consists in axial tension of the specimens that allows the continuous increase of the force from zero to the value at which the specimen cracks. The tests were carried out at ambient temperature.

The results of the static tensile test for round specimens made of MS1 steel are presented in Table 2.

Tab. 2 Summary of the results of static tensile tests on round specimens before applying heat treatment

\begin{tabular}{|c|c|c|c|c|c|c|}
\hline $\begin{array}{c}\text { Sample } \\
\text { label }\end{array}$ & $\begin{array}{c}\text { Diameter } \\
{[\mathrm{mm}]}\end{array}$ & $\begin{array}{c}\text { Young's } \\
\text { modulus } \\
{[\mathrm{GPa}]}\end{array}$ & $\begin{array}{c}\text { Plasticity } \\
\text { boundary } \\
(0.2 \% \\
\text { displacement })\end{array}$ & $\begin{array}{c}\text { Strain for } \\
\text { plasticity } \\
\text { boundary } \\
{[\%]}\end{array}$ & $\begin{array}{c}\text { Maximum } \\
\text { force } \\
{[\mathrm{kN}]}\end{array}$ & $\begin{array}{c}\text { Tensile } \\
\text { strength } \\
{[\mathrm{MPa}]}\end{array}$ \\
\hline P1_90 & 2.83 & 169.7 & 1092 & - & 7.47 & 1187.80 \\
\hline P2_90 & 2.82 & 175.0 & 1106 & 0.83 & 7.64 & 1223.25 \\
\hline P3_90 & 2.83 & 171.6 & 1113 & 0.85 & 7.69 & 1221.75 \\
\hline P4_60 & 2.74 & 173.4 & 1100 & 0.83 & 7.36 & 1247.40 \\
\hline P5_60 & 2.75 & 177.0 & 1091 & 0.78 & 7.24 & 1218.59 \\
\hline P6_60 & 2.74 & 174.1 & 1116 & 0.84 & 7.30 & 1237.92 \\
\hline P7 45 & 2.69 & 177.4 & 1043 & 0.76 & 5.95 & 1046.52 \\
\hline P8_45 & 2.76 & 193.1 & - & - & 5.44 & 908.89 \\
\hline P9_45 & 2.95 & 164.4 & 979 & 0.76 & 7.27 & 1064.22 \\
\hline
\end{tabular}


On the basis of the analysis of the results contained in Table 2, we can see that the tensile strength slightly differs depending on the building angle of the layers of the printed specimens. The specimens with printing orientation at an angle of $45^{\circ}$ have recorded the lowest strength value. Figures 9-11 show the tensile diagrams for round specimens printed at different angles in relation to the printing plane. Tensile diagrams obtained on the basis of the obtained results allow reading the value of the tensile force and other strength properties of the analyzed material. It is worth noting here that the results in the charts overlap, which proves the reliability of the research.

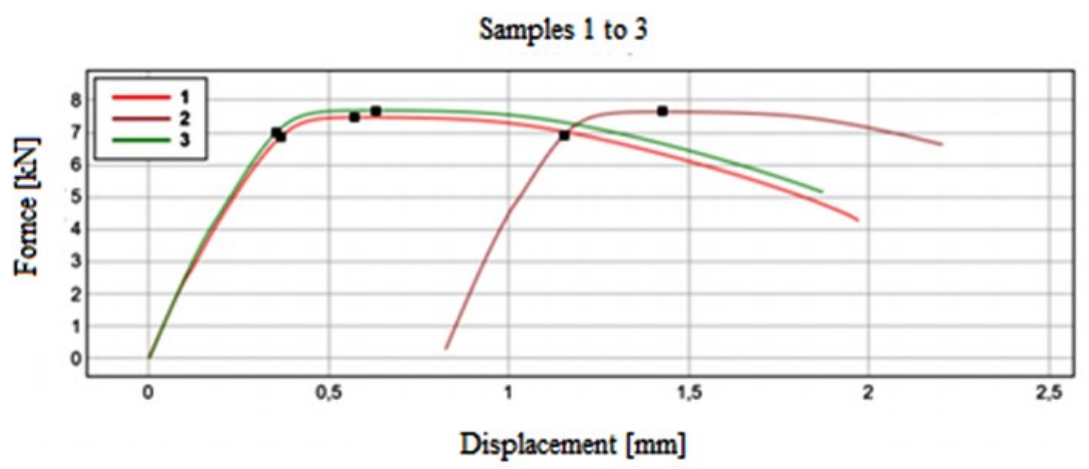

Fig. 9. Tensile test plot for specimens produced at an angle of $90^{\circ}$.

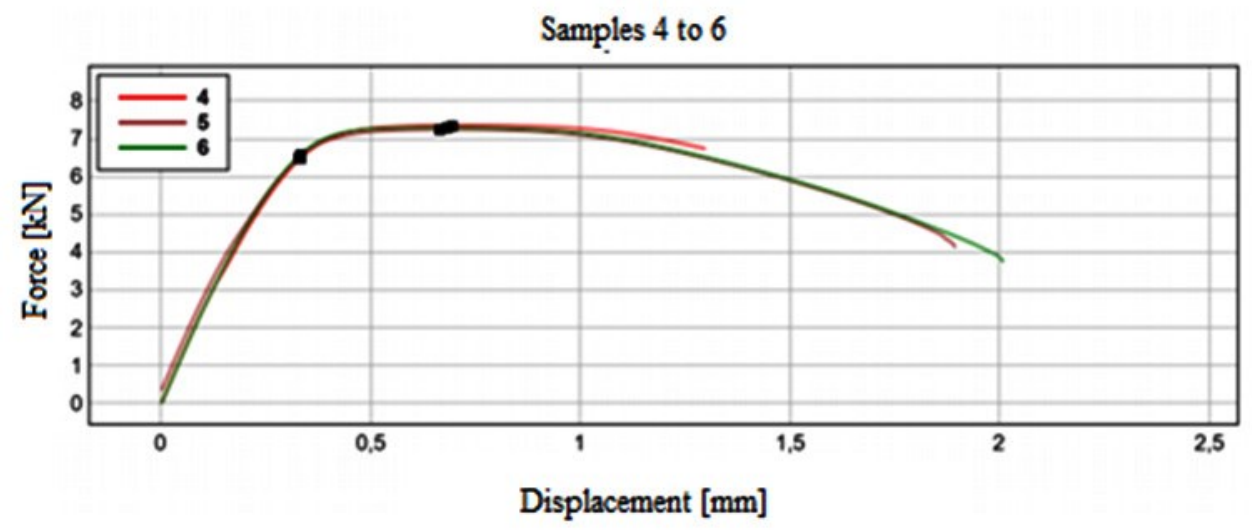

Fig. 10. Tensile test plot for specimens printed at an angle $60^{\circ}$. 


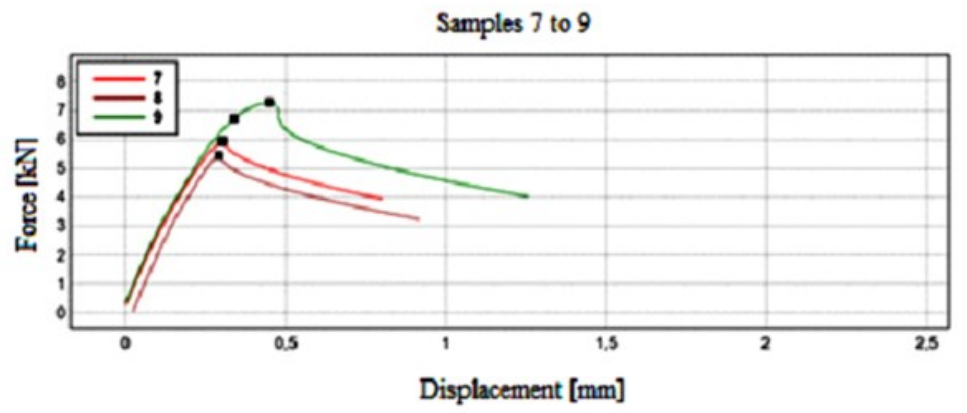

Fig. 11. Tensile test plot for specimens printed at an angle $45^{\circ}$.

Figures 12-13 contain metallographic images of two selected specimens at printed an angle of $90^{\circ}$ and $45^{\circ}$. From the analysis of the fracture image, it can be seen that the fracture image occurs along the print line, i.e. according to the angle at which the specimen was printing was executed. The crack pattern along the print line also indicates the anisotropy of materials printed with the DLMS method.

a)

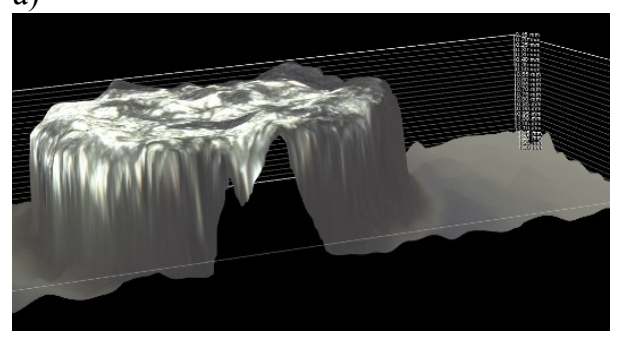

b)

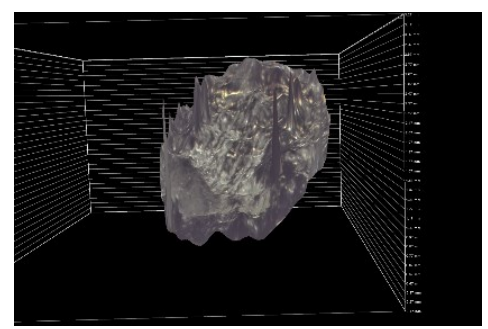

Fig. 12. Fracture of a specimen printed at the angles of a) $90^{\circ}$ b) $45^{\circ}$

a)

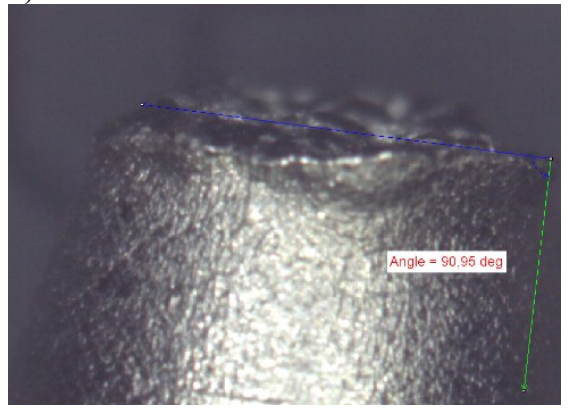

b)

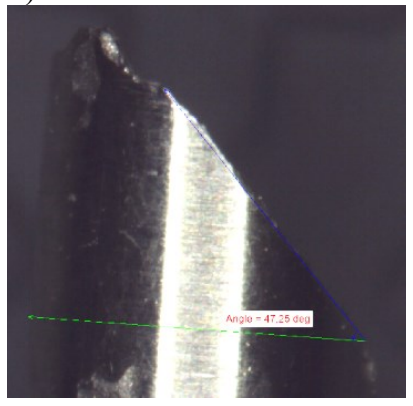

Fig. 13. Fracture of a specimen printed at the angles of a) $90^{\circ}$ b) $45^{\circ}$

The results of the static tensile test for round specimens made of MS1 steel are presented in tab. 3 


\section{PRMR 2021}

Tab. 3. Summary of test results for a static tensile test of flat specimens prior to the application of heat treatment

\begin{tabular}{|c|c|c|c|c|c|c|}
\hline $\begin{array}{c}\text { Sample } \\
\text { label }\end{array}$ & $\begin{array}{c}\text { Thickness } \\
{[\mathrm{mm}]}\end{array}$ & $\begin{array}{c}\text { Young's } \\
\text { modulus } \\
{[\mathrm{GPa}]}\end{array}$ & $\begin{array}{c}\text { Plasticity } \\
\text { boundary } \\
(0.2 \% \\
\text { displacement })\end{array}$ & $\begin{array}{c}\text { Strain for } \\
\text { plasticity } \\
\text { boundary } \\
{[\%]}\end{array}$ & $\begin{array}{c}\text { Maximum } \\
\text { force } \\
{[\mathrm{kN}]}\end{array}$ & $\begin{array}{c}\text { Tensile } \\
\text { strength } \\
{[\mathrm{MPa}]}\end{array}$ \\
\hline P1_45 & 2.43 & 185.6 & 790.74 & 1.65 & 13.44 & 933.32 \\
\hline P2_45 & 2.4 & 174.4 & 786.37 & 1.6 & 14.18 & 984.63 \\
\hline P3_45 & 2.5 & 166.0 & 793.30 & 1.84 & 14.23 & 988.17 \\
\hline P4_75 & 2.4 & 173.7 & 996.72 & 1.79 & 16.58 & 1151.65 \\
\hline P5_75 & 2.44 & 169.0 & 889.02 & 1.77 & 16.35 & 1135.21 \\
\hline P6_90 & 2.43 & 150.8 & 1008.11 & 3.19 & 17.25 & 1198.07 \\
\hline P7_90 & 2.44 & 167.0 & 969.07 & 3.14 & 17.09 & 1186.56 \\
\hline P8_90 & 2.46 & 159.7 & 995.64 & 3.03 & 17.28 & 1200.20 \\
\hline
\end{tabular}

On the basis of the analysis of the results given in tab. 3, we can see that the tensile strength increases with the printing angle of the specimens. For example, for specimens printed at an angle of $75^{\circ}$, this value is in the range of about $16 \%$ in relation to specimens taken at an angle of $45^{\circ}$.

However, for specimens printed at an angle of $90^{\circ}$, this value varies by around $22 \%$ in relation to specimens produced at an angle of $45^{\circ}$. These results prove the high anisotropy of printed materials.

Figs. 14-16 that follow contain tensile test plots developed for round specimens printed at different angles.

\section{Samples 1 to 3}

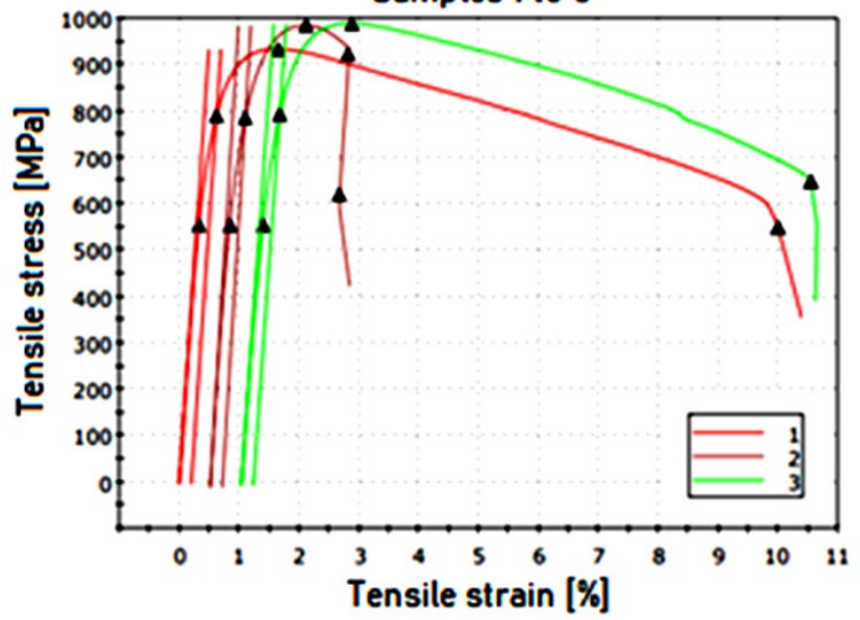

Fig. 14. Tensile test plot for specimens printed at the angle of $45^{\circ}$. 


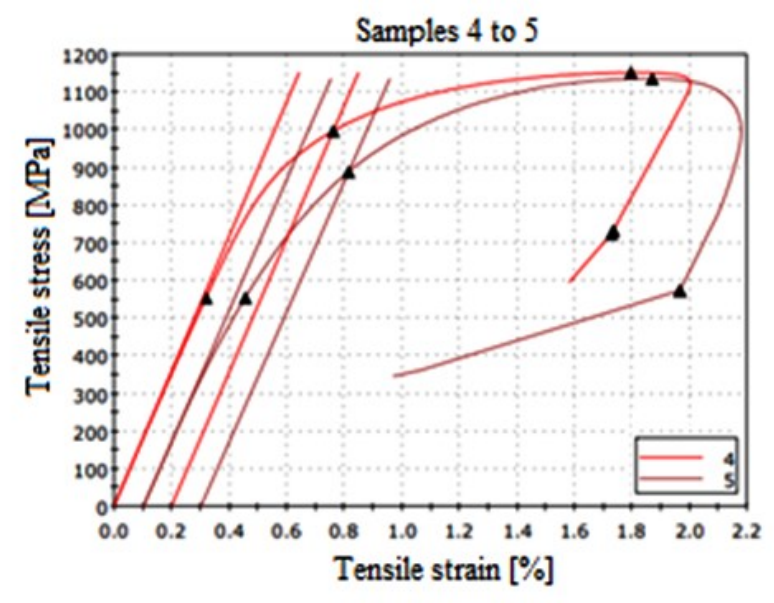

Fig. 15. Tensile test plot for specimens printed at the angle of $75^{\circ}$.

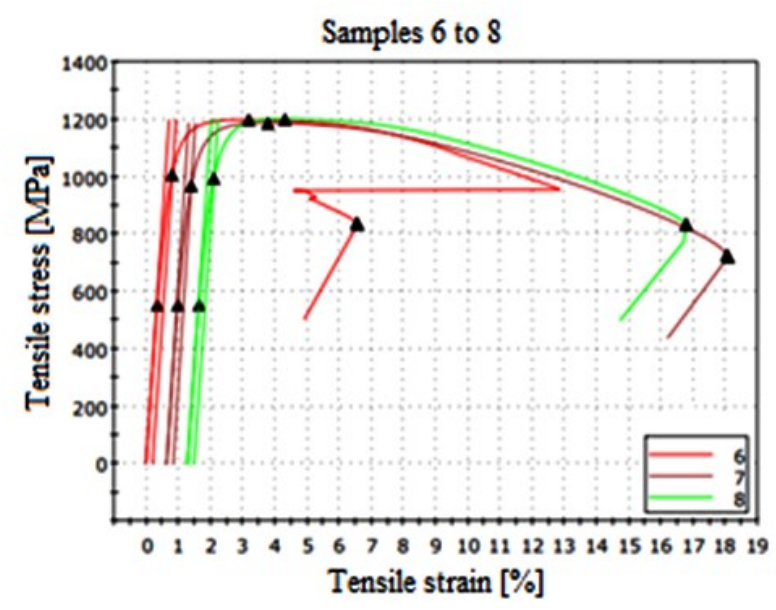

Fig. 16. Tensile test plot for specimens printed at the angle of $90^{\circ}$.

\section{Conclusions and summary}

On the basis of the analyses carried out the following conclusions can be drawn:

1. The building direction of printing layers has a effect on the strength of investigated materials.

2. The strength parameters only slightly differ from the parameters provided in the manufacturer's data.

3. The cracking of specimens occurs alonf the line of overlapping of printing layers.

4. The course of the crack along the priniting layers indicates the ocurrence of anisotrophy of the mateiral.

5. Static tests are projected for the same types of specimens following heat treatment. 


\section{References}

1. C. Buchanan, L. Gardner, Engineering Structures Journal, 180 (2019)

2. T. D. Ngoa,, A. Kashania, G. Imbalzanoa, K. T.Q. Nguyena, D. Hui, Composites Part B, 143 (2018)

3. T. Duda. L. V. Raghavan, IFAC-Papers OnLine, 49, (2016)

4. A. Simchi, F. Petzoldt H. Pohl Journal of Materials Processing Technology 141 (2003)

5. https://drukarki3D.pl/technologie/technologia-dmls/ (schemat działania SLS/DMLS)

6. Y. Kok ,X.P. Tan, P. Wang, M.L.S. Nai ,N.H. Loh, E. Liu, S.B. Tor, Materials and Design 139 (2018)

7. J. R. Lee, M.S. Lee, H. Chae, S. Y. Lee, T. Na, W.S. Kim, T.S. Jun, Materials Characterization 167 (2020)

8. Y. Wang, J. Bergstrom, C. Burman, Journal of Materials Processing Technology, 172, $1,(2006)$

9. L. Safai, J. S. Cuellar, G. Smit, A. A. Zadpoor, Additive Manufacturing 28 (2019)

10. S.A. Jawade, Rashmi. S. Joshi, S.B. Desai School, Materials Today: Proceedings (2020)

11. X.P. Tan,Y. J. Tan, C.S.L. Chow, S.B. Tor, W.Y. Yeong, Materials Science and Engineering C 76 (2017) 